\title{
Determinants for research on rare diseases
}

\author{
Francesc Palau \\ From 5th European Conference on Rare Diseases (ECRD 2010) \\ Krakow, Poland. 13-15 May 2010
}

The term rare diseases (RD) includes a wide heterogeneous group of disorders that can involve any human organ or system. In the last decade RD have been incorporated into the agenda of health-care providers and public-health authorities; however, many problems still remain to be solved and even addressed properly. Some of these issues refer to patient' care and management such as early diagnosis, quality of the information, access to treatment and rehabilitation, and appropriate multidisciplinary healthcare. Research is also necessary as it is the way to learn about mechanisms of diseases, improve diagnosis techniques and develop new therapeutic approaches. Research in psychological and social aspects of RD is also needed. Determinants for biomedical research in RD and orphan medicines affect basic science, clinical investigation, translational approaches, and transfer activities at the pharmaceutical and biotech companies, making the patient the focus of the triangle made up of the academy, hospitals and industry.

These determinants can be summarised as follows: i) The human factor: human resources for research need to incorporate new research teams into the field of RD and especially young scientists and physicians; ii) the financial factor: funds from public agencies, national and international, investment from the industry, and participation of charities and private foundations; iii) the training factor: interest in $\mathrm{RD}$ research has to be encouraged in young people at the graduate school of medicine, biological sciences, public health, and healthcare professionals to promote the professional and research interest; iv) core facilities: patients' registries and biobanks; v) the healthcare system: reorganisation of health resources and creation of centres of expertise to facilitate research into the clinical practice; vi) the social

Correspondence: fpalau@ibv.csic.es

Research Professor, Institute of Biomedicine, CSIC, and CIBER on Rare Diseases (CIBERER), Valencia, C Jaume Roig, 11, 46010 Valencia, Spain

B̈̈oMed Central $\quad 02010$ Palau; licensee BioMed Central Ltd. factor: promotion and empowerment of patients and their role as participants in clinical studies or clinical trials; vii) the political factor: RD as a main topic for public research.

Published: 19 October 2010

doi:10.1186/1750-1172-5-S1-016

Cite this article as: Palau: Determinants for research on rare diseases.

Orphanet Journal of Rare Diseases 2010 5(Suppl 1):016.
Submit your next manuscript to BioMed Central and take full advantage of:

- Convenient online submission

- Thorough peer review

- No space constraints or color figure charges

- Immediate publication on acceptance

- Inclusion in PubMed, CAS, Scopus and Google Scholar

- Research which is freely available for redistribution

Submit your manuscript at www.biomedcentral.com/submit
C Biomed Central 